\author{
MICHAEL DRUCQUER
}

As the child health surveillance programme in Britain is under scrutiny at present I report here how the service is organised in France and compare the two systems.

In France the profession has strongly resisted any movement towards nationalisation of the health services and has jealously guarded the principle of "médecin libéral." This has meant preserving an item of service system payable at the time of the consultation, though the patient can subsequently claim back about $80^{\circ} \%$ of the fee from the state. Many people also take out private insurance to cover the remaining $20 \%$. This concept of médecin liberal has led to a three tier system of health care. There are specialists who work almost exclusively in the hospitals, and "médecins géneralistes," the equivalent of our general practitioners, who work exclusively in the community. The third group of doctors have usually completed the demanding four year internship and may have progressed to registrar level. They subsequently spend part of their time working as hospital assistants in a particular specialty and the rest as a specialist, at primary care level, working from their own surgery premises in the community. There is no concept of a doctor's list, and patients are free to choose whom they consult according to how much they wish to spend and how they perceive their problem. This diversity is also reflected in the child health programme, which, although rigidly defined by law, is carried out by various health workers.

\section{Structure of the services}

Recognition that child health surveillance legislation was needed dates back to the Loi Roussel of 1874 after scandalous reports of children placed in nurseries. Not until 1945, however, was a comprehensive system created. This centres around the "service de protection maternelle et infantile"-equivalent to Britain's network of child health clinics. The service is run by doctors, most of whom have had several years' hospital paediatric experience; midwives (a small number of antenatal examinations are also performed); "puéricultrices"-nurses with paediatric training in which particular emphasis has been placed on the intricacies of infant feeding; social workers; and psychologists. The doctor is allowed to prescribe only vitamins. The puéricultrice undertakes one visit to each newborn infant at some time in the first few months of life, but home visiting is carried out much less frequently than in England and is a relatively new development. The service de protection maternelle et infantile conducts about two and a half million examinations a year, but this represents only about a quarter of all the routine examinations performed. The rest are carried out either in "dispensaires," such as those run by the French railways for their employees, or "en ville" at the surgery of a paediatrician or generalist. Consultations at the service de protection maternelle

Department of Paediatrics, Hôpital Ambroise-Paré, Boulogne 92100, France

MICHAEL DRUCQUER, $\mathrm{MB}, \mathrm{DCH}$, foreign medical resident are free, but many patients remain loyal to their accustomed doctor and prefer to pay.

\section{Surveillance and vaccination programmes}

Concern about the levels of childhood morbidity and mortality in France over the past 10 years has led to a determined drive towards improving the services. Real progress has been made: the perinatal mortality has declined from 21.3 per 1000 in 1972 to 12.9 per 1000 in 1980 . Many of the extensive changes that were enacted affected obstetrics and perinatal hospital care-for example, the closure of many small obstetric clinics, increased antenatal surveillance, more money for neonatal intensive care, and the setting up of doctor accompanied ambulances for transport of sick children-but the child health surveillance programme was not forgotten. Government recommendations enacted in 1978 are that nine examinations should be performed in the first year of life, three in the second year, and two each year for the next four years. The examinations follow a similar pattern to those in England, with surveillance of growth, feeding, psychosocial development, special senses, etc. If a problem arises a child may be referred either to a hospital specialist or to one of the government run "centres medico psychopédagogique," where a team of speech therapists, physiotherapists, psychologists, doctors, and social workers can initiate assessment and treatment.

What distinguishes the French system, however, is that since 1973 the examinations at 8 days, 9 months, and 2 years are not only deemed obligatory but have to be performed for the mother to be able to claim the child benefit allowance. No examination means no money; thus over a period of two years a mother stands to lose a minimum of $£ 150$ in benefits plus an additional much smaller allowance given to those who breast feed.

Similarly, the vaccination programme, except for pertussis and measles, is compulsory for all children in the absence of contraindications. A BCG examination is performed before the age of 5 , often in the first month of life, and is rigorously controlled by a skin test after three months. If this is negative the BCG is repeated. Triple vaccine and polio are given at 4, 5, and 6 months with recalls at 18 months, 5 years, 10 years, and 16 years. In practice, there is no withdrawal of child benefits if the vaccinations are not performed, but, in addition to reminder letters and probably also a visit from the social worker, there is the even more persuasive sanction that it is not permitted to send a child to a nursery school or primary school unless the vaccinations are in order. With such sanctions it is not surprising that there has been no fall off in the vaccination rate as there has been recently in Britain.

\section{Could we, or should we, adopt this system?}

I can imagine the protestations that would greet the introduction of such a scheme in Britain, a country where seat belt legislation was considered by many to be an assault on personal liberty, and I wonder whether it would be politically feasible. In France, however, despite its political volatility, people have 


\section{Statutory sick pay and certification}

The General Medical Services Committee's secretariat has given the following advice to local medical committees about certification under the Employers Statutory Sick Pay scheme, which came into effect on 6 April.

Employers, who include general practitioners, must now make minimum payments for absences of up to eight weeks a year to employees who are incapable of work through sickness. They must not only satisfy themselves that the employee is genuinely incapacitated but must be able to justify this decision to the Department of Health and Social Security, which will assume responsibility for sickness payments after the eighth week-that is, eight weeks in any one financial year. It is up to the individual employer to decide what evidence of incapacity is acceptable and this may be a form MED 3, which a general practitioner is required under his terms of service to provide to patients free of charge in support of claims for statutory sick pay or Social Security benefit for illnesses lasting more than seven days. The requirements for medical certification by general practitioners remain unchanged; no more and no fewer forms MED 3 will be requested than before.

The secretariat has received several inquiries about the disclosure of confidential clinical information to employers on form MED 3. In practice, MED 3 has for many years been shown to employers as proof of incapacity. Although a general practitioner should normally give "a precise and accurate diagnosis," he may be able to arrive at a form of words which is acceptable for the purposes of statutory sick pay but does not cause the patient embarrassment.

Since it is the responsibility of the patient to provide evidence of incapacity to his employer it has been agreed that form MED 3 will be given to the patient and not sent directly to the employer or to the Department. Paragraph 31 of the terms and conditions of service makes this clear.

\section{Regional medical service}

If the employer refuses to submit the form to his employer, and if the employer withholds statutory sick pay, the employee may "ask the insurance officer to decide whether statutory sick pay is payable. If the insurance officer has insufficient medical evidence on which to make a decision he may ask for a reference to the regional medical service. The regional medical service will consult the patient's own doctor before an examination is arranged" and a ruling on eligibility for statutory sick pay made.

\section{BMA membership at 31 March}

\section{General practitioners}

Senior hospital doctors

Junior hospital doctors

Community medicine and community health doctors

Civil Service doctors

Armed forces doctors

Occupational health

Medical academic staff

Members in practice but not identifiable by group

Total in practice

Retired members

Total UK membership

Total overseas membership

Local medical committees have been reminded that if they do not consider that the patient has been or is unfit for work a doctor's statement should not be supplied. It is for the patient to justify his absence to his employer. learnt, over a period of about 300 years, how to live with an authoritarian and powerful bureaucracy that impinges on everyday life in ways that would be unacceptable to most people in Britain.

Although not within the brief of this article, it is worth mentioning that there are other examinations that are compulsory in France. The "examen prénuptial" consists of a physical examination of both parties as well as blood tests. A certificate of its completion must be presented to the registrar before a marriage can be performed. Antenatal examinations are also compulsory and tied to maternity benefits.

Although the medical practice is broadly similar, certain differences are apparent. Hip $x$ ray examinations are performed systematically after the age of 4 months in areas of high incidence of congenital dislocation or if there is a family history, and double nappies are recommended for breech delivery babies. Vitamin $\mathrm{D}$ is given to all children before the age of 2 years. Vaccinations are generally given subcutaneously into the back, at the level of the scapulae. Breast feeding is discouraged beyond the age of 6 months - in practice, most French mothers stop at 3 months. French culinary expertise is reflected in the instructions given to mothers by the service de protection maternelle et infantile. Trout, veal, and Camembert are all recommended for children over 5 months, and detailed instructions are given about the cooking method. For diarrhoea, carrot purée diluted half and half with milk remains a favourite first step remedy-my limited experience in prescribing this is that it actually works.

\section{“Carnet de santé"}

The linchpin of the programme rests, however, not with one doctor or organisation but with the document called the "carnet de santé." This detailed booklet of 103 pages is kept by the parents and follows the child's health from birth to the age of 20 and is filled in by the doctor at each visit. There are details of the birth including Apgar scores, growth percentile curves, records of immunisations, feeding regimens, and details of any hospital admissions. Parents are advised to show the carnet only to those covered by the "secret professionel" (code of medical confidentiality) and are asked to bring it to each medical consultation. Although the booklet is considered by some to be too complicated-for example, the growth percentile curves often engender unnecessary parental anxiety if the baby does not conform exactly to the norm-it remains an indispensable document for health workers seeing the child for the first time. It is particularly necessary in France, where parents are free to take their child to several different doctors at primary care level, but properly kept the "carnet de santé" would be a useful record in any health system.

\section{Conclusion}

The preventive child health system in France is distinguished by its medicopolitical context of médecin libéral, by its strictly followed rules and regulations, by the carnet de santé, and by the fact that the child benefit allowance is given only if certain examinations are undertaken. If we wish Britain's system of child health services to improve we may have to borrow some of these elements from our colleagues on the other side of the Channel.

I should like tc thank Professor J P Gallet of the Hôpital AmbroiseParé and the staff of the service de protection maternelle et infantile in Boulogne for their help in preparing this article. 